\title{
THE EFFECT OF PLASTICIZER ON MECHANICAL PROPERTIES OF THE CEMENT PASTE WITH FINE GROUND RECYCLED CONCRETE
}

\author{
JAROMÍR HRŮZA*, ZDENĚK PROŠEK \\ Czech Technical University in Prague, Faculty of Civil Engineering, Thákurova 7, 16629 Prague 6, Czech \\ Republic \\ * corresponding author: jaromir.hruza@fsv.cvut.cz
}

\begin{abstract}
This article deals with the usage of recycled concrete, which arises from the demolition of concrete structures. The work is focused on the development of mechanical properties (Young's modulus, compressive and flexural strength) depending amount of plasticizer in the mixture. In the experiment were prepared three sets of samples with different amounts of plasticizer $(0,0.5$ and 1.0 wt. $\%$ of cement). Each pair always contained reference samples (only cement) and 35 wt. \% of fine ground recycled concrete. One of the main reasons for the use of finely ground recycled concrete was a certain substitution of cement in the mixture, which is the most expensive component. Development of Young's modulus was measured by the nondestructive method. The aim of the experiment was to determine the effect of plasticizer on the resulting physical and mechanical properties of cement pastes with fine ground recycled concrete.
\end{abstract}

KEYWORDS: Recycled concrete, Young's modulus, plasticizer, mechanical properties, cement replacement.

\section{INTRODUCTION}

Already since the first production of concrete, which has become the most widely used composite material, attempts have been made to improve the properties of this material. For adjustment of various concrete properties are used plasticizers, delayers or accelerators of solidification and hardening, aerating additives, hydrophobic additives, waterproofing and anti-frosting additives, etc. However, it is often the case that the use of the additives or admixtures to improve the desired properties cause the deterioration of others properties, and it is, therefore, necessary to evaluate the positive and also negative aspects of the used additives. The use of plasticizers for the adjustment of cement-based composites is currently relatively widespread due to the reduction of the water coefficient and the achievement of greater strengths, for example in high-performance concrete. Plasticizers are organic macromolecular substances adsorbing on the surface of cement grains, allowing them to change their electric charge, disperse particle agglomerates and thereby modify the consistency of fresh concrete [1].

With recycled concrete and plasticizing additives, we meet in the area of high-performance concrete. A relatively large number of studies are focused on the use of recycled concrete aggregates in highperformance concrete, where recycled concrete is mostly a natural stone replacement [2 [5]. This is the use of recycled concrete in the form of gravel of different fractions. The use of recycled fine concrete aggregates is not so widespread because it is work with fine ground recycled concrete which is overshadowed by the use of coarse recycled aggregate and brings more problems in designing the mixture in terms of water absorption. This is the reason why much less experts deal with this topic [6] 8 . The use of fine ground recycled concrete in cement paste mixtures with a plasticizer and without the use of aggregate is practically not found.

\section{MATERIALS AND METHODS}

In the experiment was made the design of cement mixtures with fine ground recycled concrete, plasticizer and water. The aim was to propose basic mixtures with identical or similar workability. This means that the water-cement ratio has varied with each mixture $(\mathrm{w} / \mathrm{c}=0.23$ to 0.38$)$ due to the substitution of 35 wt. \% of Fine Ground Recycled Concrete (FGRC) as the absorption requirements of FGRC for water is far greater than for cement. The water-cement ratio adjustment to achieve the desired processability of the mixture was also influenced by the added amount of plasticizer $(0,0.5$ and 1.0 wt. $\%$ of cement). The polycarboxylate-based plasticizer has been used to reduce the water-cement ratio to achieve greater strengths and less pore formation in the matrix, which is also affected by the amount of mixing water. The plasticizer was added to the fresh mixture which was prepared by hand mixing.

Fine ground recycled concrete was used as a filler with certain bonding properties of unhydrated cement grains in FGRC. As a binder was used the Portland cement CEM I 42.5 R from Radotín (Prague, CZ) 


\begin{tabular}{lcccccc}
\hline \multicolumn{1}{c}{ Set } & $\begin{array}{c}\text { Weight } \\
\text { of } \\
\text { Cement } \\
{[\mathrm{g}]}\end{array}$ & $\begin{array}{c}\text { Weight } \\
\text { of } \\
\text { FGRC } \\
{[\mathrm{g}]}\end{array}$ & $\begin{array}{c}\text { w/c } \\
{[-]}\end{array}$ & $\begin{array}{c}\text { Weight } \\
\text { of } \\
\text { Water } \\
{[\mathrm{g}]}\end{array}$ & $\begin{array}{c}\text { Plasticizer } \\
{[\mathrm{g}]}\end{array}$ & $\begin{array}{c}\text { Plasticizer } \\
\text { [wt. \%,of } \\
\text { Cement] }\end{array}$ \\
\hline A (Cem) & 1000 & 0 & 0.30 & 300 & 0.00 & 0.0 \\
B (Cem + FGRC) & 650 & 350 & 0.38 & 380 & 0.00 & 0.0 \\
C (Cem + 0.5plast) & 1000 & 0 & 0.25 & 250 & 5.00 & 0.5 \\
D (Cem+FGRC+0.5plast) & 650 & 350 & 0.35 & 350 & 3.25 & 0.5 \\
E (Cem + 1.0plast) & 1000 & 0 & 0.23 & 230 & 10.00 & 1.0 \\
F (Cem+FGRC+1.0plast) & 650 & 350 & 0.32 & 320 & 6.50 & 1.0 \\
\hline
\end{tabular}

TABLE 1. Overview of the mixtures composition at a weight of $1000 \mathrm{~g}$ mixture.

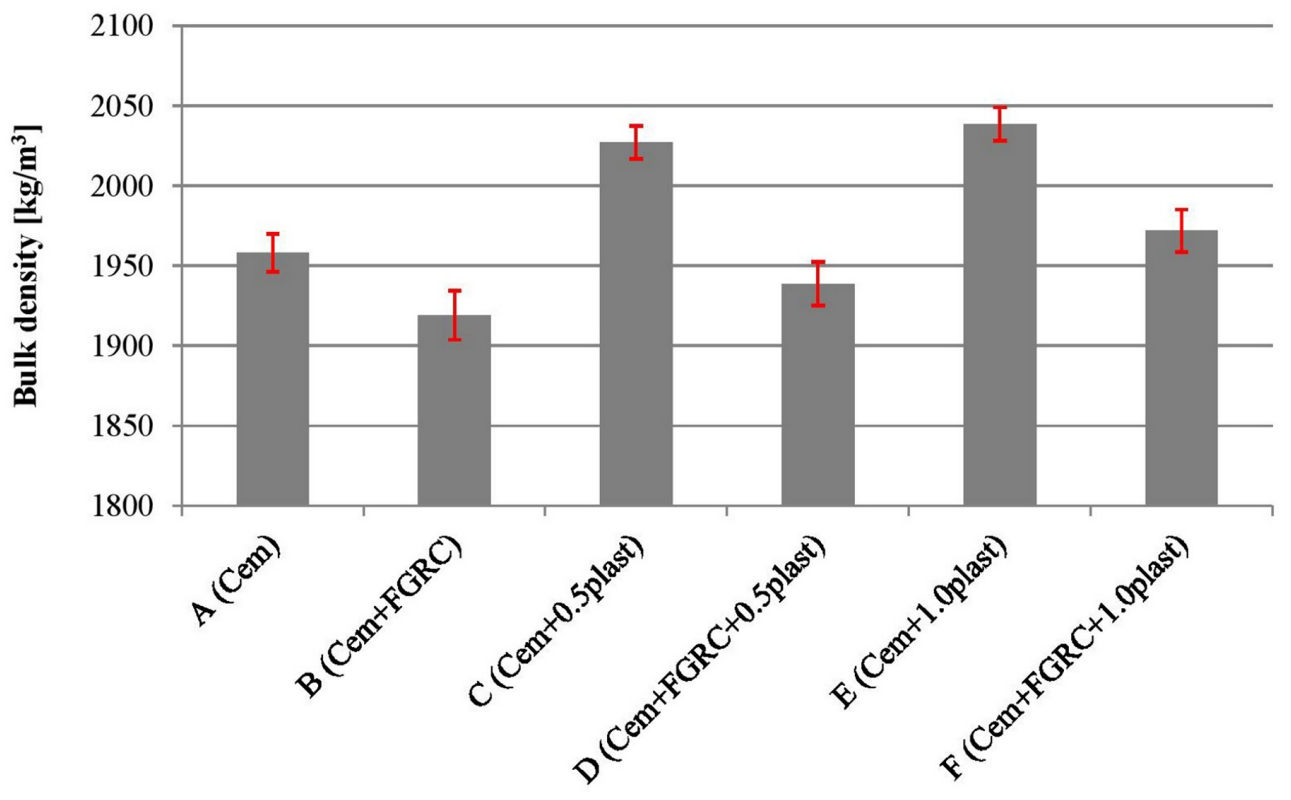

FiguRE 1. Bulk density of the produced samples, standard deviation.

was used. Fine ground recycled concrete was obtained from road gutters. The road gutters were coarsely crushed to particle-size fraction $0-63 \mathrm{~mm}$. For the intended use as a filler, or partial replacement of cement, the fraction of $0-16 \mathrm{~mm}$ was separated by sieving and further was modified by high-speed grinding. The composition of the proposed mixtures and the weight of the individual components for the sample production are shown in Table 1

The reference set labeled as $\mathrm{A}$ is made only of cement and water. The pair of sets $\mathrm{A}+\mathrm{B}, \mathrm{C}+\mathrm{D}$ and $\mathrm{E}+\mathrm{F}$ differ by the amount of plasticizer contained, and each pair contains a mixture without and with 35 wt. \% of FGRC (Table 1). The water-cement ratio was calculated from the dry mixture. The prepared mixture was subjected to the spillage test and then placed into molds of dimension $160 \times 40 \times 40 \mathrm{~mm}$. Samples, which were made for this experiment, had been stored for 28 days in air at room temperature.

The resonance method was used for measuring of the Young's modulus of elasticity of the samples. It is a method of nondestructive character, which is together with measurement speed its advantage. The method is based on calculating of the dynamic modulus and dynamic shear modulus from the measured basic resonance frequencies of longitudinal, lateral (flexural) and torsional oscillation. The resonance frequencies were measured in the laboratory using a measuring assembly Brüel\&Kjær, which consisted of an acceleration sensor Brüel\&Kjær type 4519-003, impact hammer Brüel\&Kjær type 8206, measuring station Brüel\&Kjær Fron-end 3560B-120 and the control notebook [9].

The flexural strength of cement mortar samples was tested by a destructive method a three-point bend. For bending tensile testing was used apparatus the Heckert type FP100 with a maximum possible loading force of $100 \mathrm{kN}$ with a press speed of $6 \mathrm{~mm} / \mathrm{min}$. The distance of the support supports of the test beams was $100 \mathrm{~mm}$. The resulting flexural strength of a given set is an arithmetic mean of 3 measurements. Compressive strength was determined on fractured samples (halves) after the flexural strength test. The compression strength test load over the previous test was $20 \mathrm{~mm} / \mathrm{min}$. Mea- 


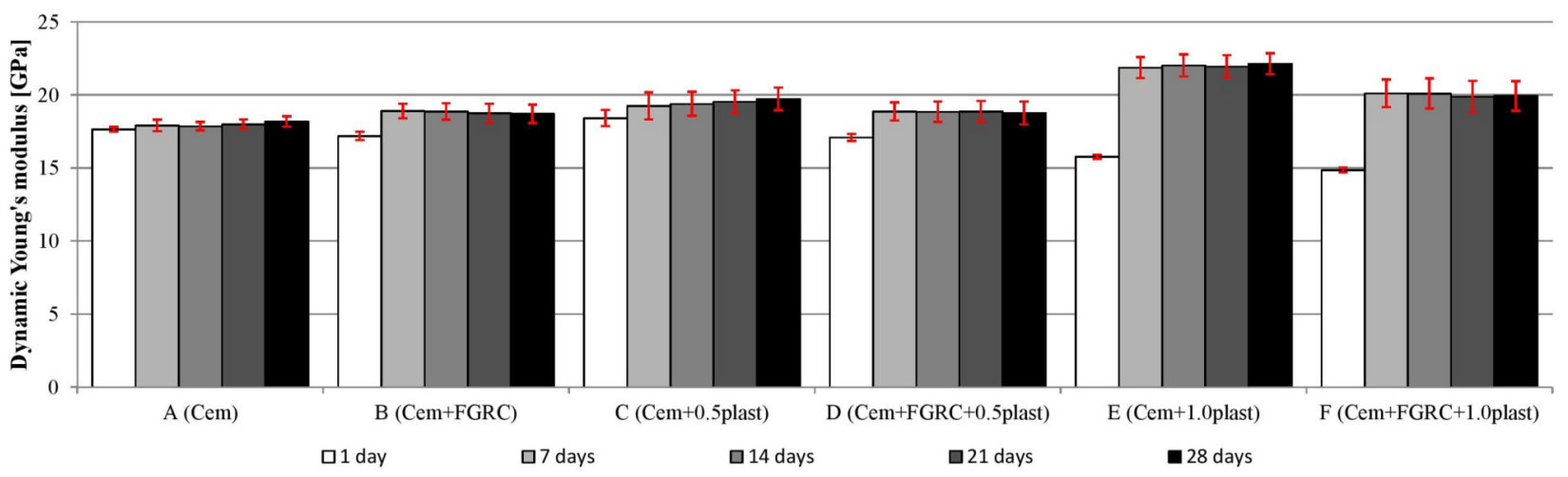

Figure 2. The dependence of the Dynamic Young's modulus on the amount of plasticizer (plasticizer in wt. \% of cement) and fine ground recycled concrete in time (longitudinal oscillation), standard deviation.

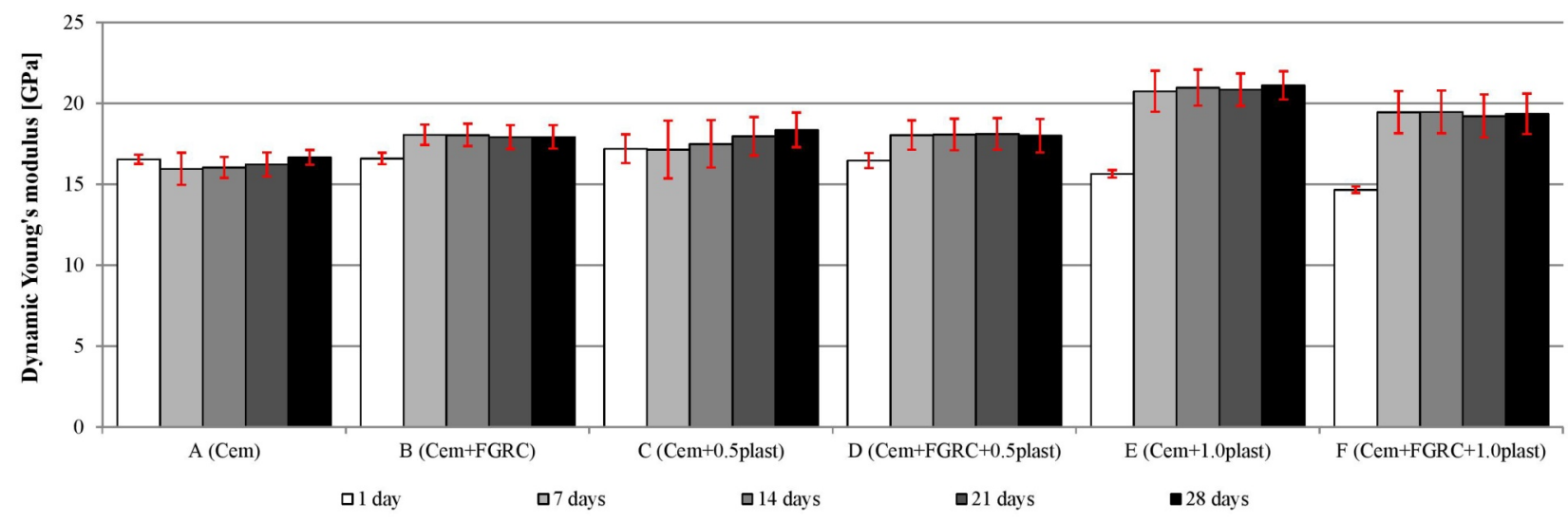

Figure 3. The dependence of the Dynamic Young's modulus on the amount of plasticizer (plasticizer in wt. \% of cement) and fine ground recycled concrete in time (flexural oscillation), standard deviation.

surement of the compressive strength was performed on five samples from each set.

\section{EXPERIMENTAL RESUlts}

From the bulk density overview in Figure 1 can be observed a clearly visible trend in each pair of samples $(\mathrm{A}+\mathrm{B}, \mathrm{C}+\mathrm{D}, \mathrm{E}+\mathrm{F})$. We see that samples without finely ground recycled concrete have a higher bulk density than those in which 35 wt. \% cement is replaced by recycled concrete. Further, we can notice the increase in the values of bulk density with the increasing amount of added plasticizer. From these results, it can be assumed that the plasticizer affects the increase of bulk density.

The following graphs (Figure 2, Figure 3) show the development values of the dynamic modulus of elasticity of each set depending on the age of the concrete (from 1 to 28 days) with 0 and 35 wt. \% recycled concrete (FGRC) and various amounts of plasticizer (0, 0.5 and $1.0 \%$ by weight of cement). As first the values for longitudinal oscillation were evaluated for each set (Figure 2). To check the accuracy of the results the values for flexural oscillation were also evaluated (Figure 3). Because the values of both graphs (Figure 2 and Figure 3) are almost identical, we can say that the measurement was done properly.

From the presented results of the development of the dynamic modulus of elasticity (Figure 2 , Figure 3 . we can see that the dynamic moduli of elasticity of all mixtures are approximately the same, only the set E exceeds $20 \mathrm{GPa}$. This also confirmed that 35 wt. \% FGRC will not adversely affect the resulting values. An interesting finding is the higher values of Set D with the addition of recycled concrete (FGRC) and 0.5 wt. \% of the plasticizer compared to the reference set (A). We can only assume that the presence of plasticizer has caused higher values of Dynamic Young's modulus. This means that the mixture (set D) with $35 \mathrm{wt}$. \% of the cement replacement with fine ground recycled concrete achieves a higher modulus of elasticity due to the reduced water-cement ratio. We can also notice a sharp increase in values after the first day of age for the sets $\mathrm{E}$ and $\mathrm{F}$, i.e. the mixtures with $1.0 \mathrm{wt}$. \% of plasticizer. The phenomenon of this kind is only visible for mixtures containing the largest amount of plasticizer. It is likely that the plasticizer caused a robust jump of values of Dynamic Young's modulus between first and seventh day. If we compare the blends with the added plasticizer, we see a slight improvement in the case of a larger amount of plasti- 


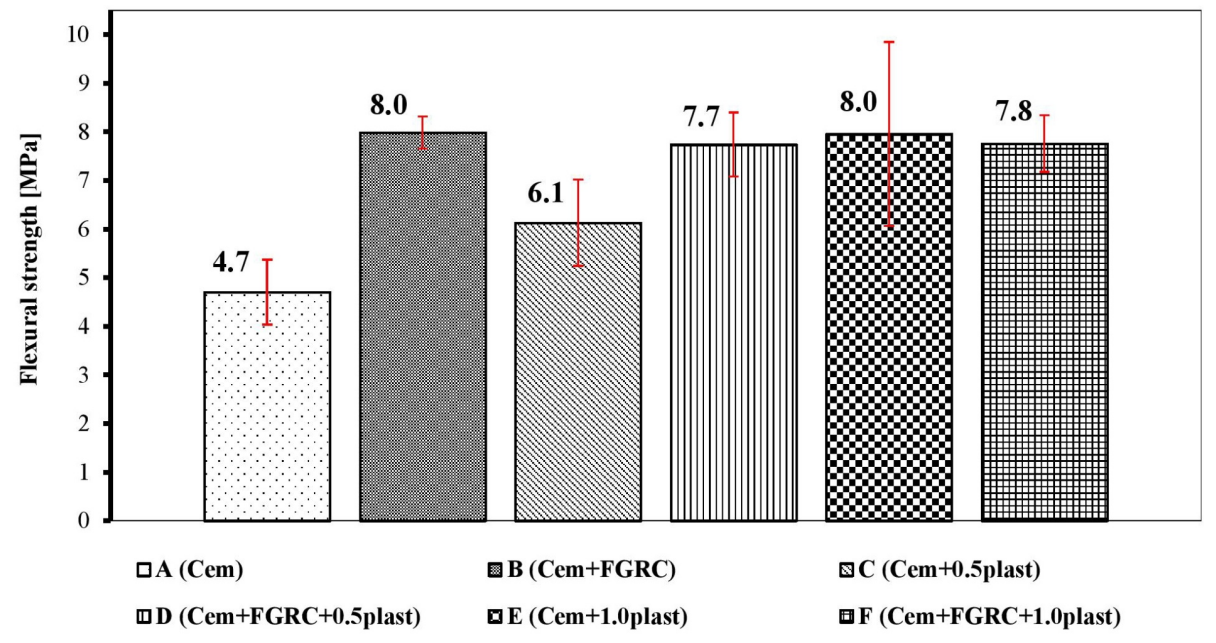

FiguRE 4. Flexural strength of 28-day old samples, standard deviation.

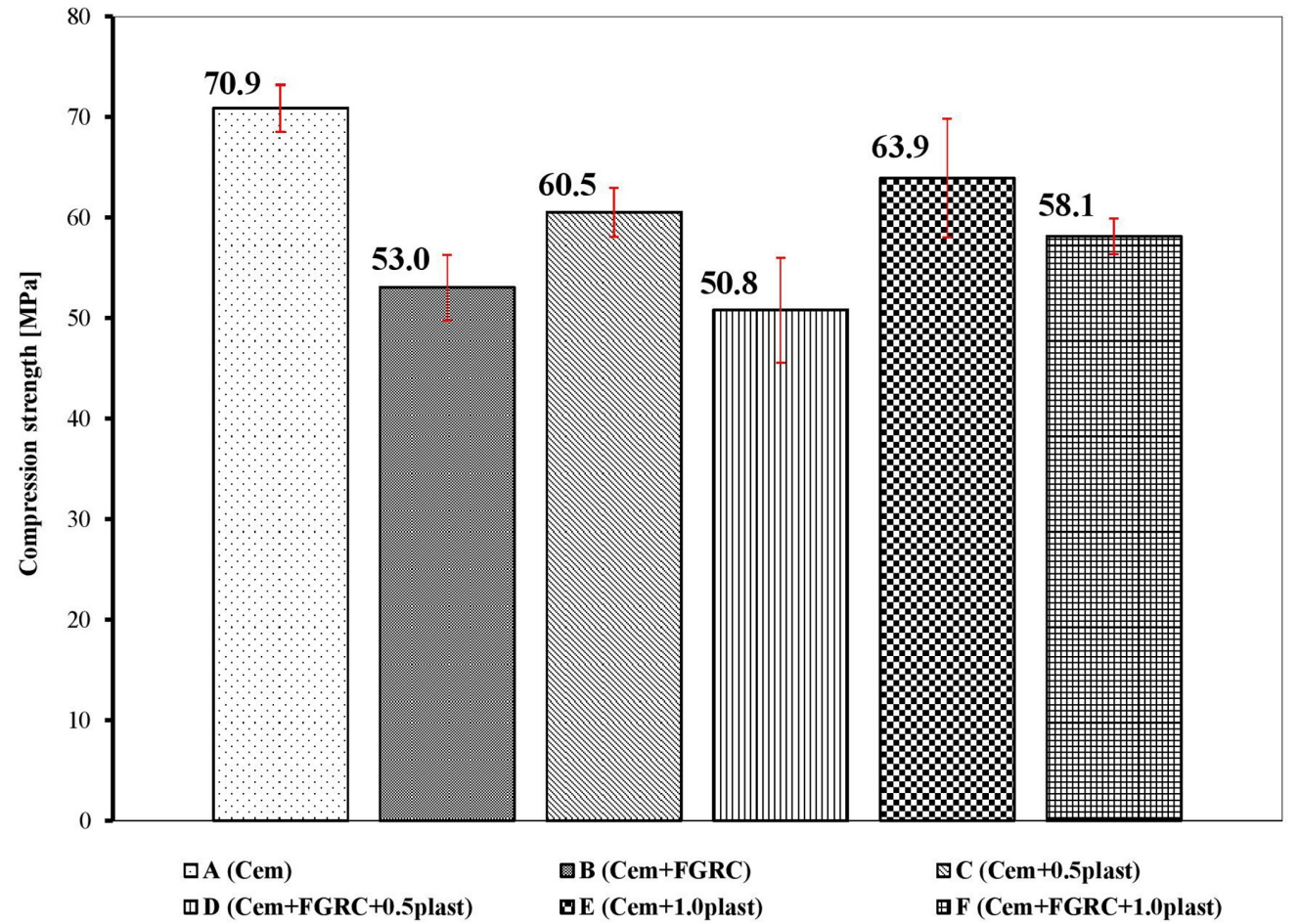

FiguRE 5. Compressive strength of 28-day old samples, standard deviation.

cizer in the mixture. When comparing mixtures B, D and $\mathrm{F}$, we conclude that the plasticizer affects the resulting values of Dynamic Young's modulus relatively little (max. about $1.2 \mathrm{MPa}$ ).

The flexural strength (Figure 4) was improved with samples without recycled concrete (A, C, E) with increasing amounts of plasticizer. On the other hand, we can't see virtually any difference or increasing trend of samples with fine ground recycled concrete (B, D, F). It has been found that the plasticizer does not affect the flexural strength of the cement pastes with recycled concrete.

From the compression strength graph (Figure 5), is visible the decrease of compression strength of the samples with the added plasticizer without recycled concrete. Thus, we can observe the adverse effect of the plasticizer on the compressive strength of the samples only with cement. If we focus on samples with fine ground recycled concrete and plasticizer, we will see a slight decrease in compressive strength of set D with $0.5 \mathrm{wt}$. \% plasticizer. On the other hand, the set $\mathrm{F}$ with the largest amount of plasticizer shows an overall improvement and an increase of strength about 5.1 MPa compared with the samples without plasticizer (set B). 


\section{Conclusions}

The purpose and objective of the experiment were to design cement mixtures with an acceptable amount of fine ground recycled concrete and plasticizer to determine the effect of the plasticizer on the resulting mechanical and physical properties. Mixtures of similar consistency and workability were designed by adjusting the water-cement ratio for each mixture.

Based on the results of the tests presented in this experiment were drawn the following conclusions:

- The bulk densities of mixtures with the FGRC are smaller than the bulk densities of the reference mixtures.

- Adding the plasticizer increases the bulk density of all mixtures.

- The added plasticizer practically does not affect the dynamic modulus of elasticity of samples with FGRC.

- Improved compressive strength after addition of 1.0 wt. $\%$ plasticizer.

- The Greater amount of plasticizer (1.0 wt. \%) affects compressive strengths more favorably than smaller amount of plasticizer (0.5 wt. \%).

\section{ACKNOWLEDGEMENTS}

This was financially supported by the Czech Science Foundation research projects GACR 17-06771S and by the Czech Technical University in Prague project SGS16/201/OHK1/3T/11. The authors also thank the Center for Nanotechnology in Civil Engineering at the Faculty of Civil Engineering, Czech Technical University in Prague and the Joint Laboratory of Polymer Nanofiber Technologies of the Institute of Physics, Academy of Science of Czech Republic, and the Faculty of Civil Engineering, Czech Technical University in Prague.

\section{REFERENCES}

[1] M. Zajíček. Chemické přísady do betonu a malt. 2008 [cit 2016-11-17] Available from: http://www asb-portal cz/stavebnictvi/materialy-a-vyrobky/cihlytvarnice/chemickeprisady-do-betonu-amalt 2008.

[2] A. Ajdukiewicz, A. Kliszczewicz. Influence of recycled aggregates on mechanical properties of hs/hpc. Cement and concrete composites 24(2):269-279, 2002.

[3] T.-Y. Tu, Y.-Y. Chen, C.-L. Hwang. Properties of hpc with recycled aggregates. Cement and concrete research 36(5):943-950, 2006.

[4] B. V. Kumar, H. Ananthan, K. Balaji. Experimental studies on utilization of recycled coarse and fine aggregates in high performance concrete mixes. Alexandria Engineering Journal 2017.

[5] P. Pereira, L. Evangelista, J. De Brito. The effect of superplasticizers on the mechanical performance of concrete made with fine recycled concrete aggregates. Cement and concrete composites 34(9):1044-1052, 2012.

[6] E. Ledesma, J. Jiménez, J. Fernández, et al. Properties of masonry mortars manufactured with fine recycled concrete aggregates. Construction and building materials 71:289-298, 2014.

[7] Z. Zhao, S. Remond, D. Damidot, W. Xu. Influence of fine recycled concrete aggregates on the properties of mortars. Construction and Building Materials 81:179-186, 2015.

[8] C. Neno, J. d. Brito, R. Veiga. Using fine recycled concrete aggregate for mortar production. Materials research 17(1):168-177, 2014.

[9] J. Hrůza. Design of masonry elements with use of recycled concrete. Prague 2016. 